\title{
Calculation of Embryo/Fetus Dose in Pregnant Thyroid Patients Who Have Accidentally Received Radioiodine
}

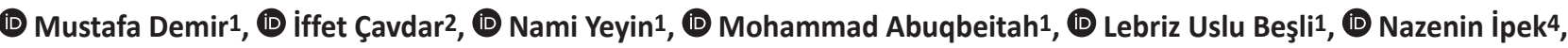 \\ (D) Mehmet Buğrahan Düz33, (D) Mehmet Seven³ \\ 1istanbul University-Cerrahpaşa, Cerrahpaşa Medical Faculty, Department of Nuclear Medicine, Istanbul, Turkey \\ 2 istanbul University Faculty of Science, Department of Nuclear Physics, Istanbul, Turkey \\ 3istanbul University-Cerrahpaşa, Cerrahpaşa Medical Faculty, Department of Medical Genetic, Istanbul, Turkey \\ ${ }^{4}$ Nişantaşı University Faculty of Engineering and Architecture, istanbul, Turkey
}

\section{Abstract}

Objective: The aim of this study was to calculate the embryo/fetus dose in pregnant patients who have accidentally received radioiodine (131I) and to evaluate the termination of pregnancy by giving teratological advice to the family.

Methods: In this study, fetus dose was calculated in 16 patients who were referred to our department following the application of ${ }^{131}$ I radioisotope for diagnosis and treatment in different nuclear medicine centers.

Results: Mean embryo/fetus dose of three pregnant patients, who received $0.37 \mathrm{MBq}(10 \mu \mathrm{Ci})^{131}$ I orally for thyroid uptake test, was calculated as $0.063 \mathrm{mGy}$. For uptake/ scintigraphy test, $1.85 \mathrm{MBq}(0.05 \mathrm{mCi})^{131}$ I was applied to six patients, and the calculated mean fetal dose was $0.13 \mathrm{mGy}$ and fetal thyroid dose was $1073 \mathrm{mGy}$ (1.073 Gy). Mean embryo/fetus dose of three patients who received mean $185 \mathrm{MBq}(5 \mathrm{mCi}){ }^{131} \mathrm{I}$ orally for whole body scintigraphy was calculated as $13.2 \mathrm{mGy}$. One of two patients with hyperthyroidism was administered $370 \mathrm{MBq}(10 \mathrm{mCi})^{131} \mathrm{I}$ orally and the embryo/fetus dose was calculated as 26.64 mGy and fetal thyroid dose was calculated as $215340 \mathrm{mGy}(215.34 \mathrm{~Gy})$. The other patient with hyperthyroidism received $481 \mathrm{MBq}\left(13 \mathrm{mCi}\right.$ ) ${ }^{131} \mathrm{I}$ and embryo/fetus dose was calculated as $34.63 \mathrm{mGy}$. One of two patients diagnosed with thyroid cancer received $3700 \mathrm{MBq}(100 \mathrm{mCi})^{131} \mathrm{I}$ and the embryo/fetus dose was calculated as $266.64 \mathrm{mGy}$. The other patient with thyroid cancer received $5555 \mathrm{MBq}(150 \mathrm{mCi}){ }^{131} \mathrm{I}$ at $15^{\text {th }}$ gestational week, and fetus dose was calculated as $377.8 \mathrm{mGy}$ and fetal thyroid dose was calculated as $3221.9 \mathrm{~Gy}$.

Conclusion: Diagnostic ${ }^{131} \mathrm{I}$ administration before the $10^{\text {th }}$ week of pregnancy induces insufficient radiation dose for termination of pregnancy. Whilst, the embryo/fetus dose in pregnant women with high doses of ${ }^{131} \mathrm{I}$ rise up to more than $100 \mathrm{mGy}$ and these cases shoulde be therefore evaluated in terms of termination of pregnancy.

Keywords: Fetus dose, fetal thyroid dose, radiation dose

\section{INTRODUCTION}

Radioiodine $\left({ }^{131} \mathrm{I}\right)$ has been used for many years in the diagnosis and treatment of hyperthyroidism (HTT) and thyroid cancer. Thyroid uptake test (TU) is performed for diagnostic purposes and/or scintigraphic imaging, with using $365 \mathrm{keV}$ using $365 \mathrm{keV}$ energy gamma rays following oral administration of low dose ${ }^{131}$ I, such as $0.37-1.85 \mathrm{MBq}(10-50 \mu \mathrm{Ci})$. In addition to gamma rays, ${ }^{131} \mathrm{I}$ emits beta particles with $606 \mathrm{keV}$, which are used for treatment. $222-1110 \mathrm{MBq}(6-30 \mathrm{mCi})$ is used for the HTT and 1110-7400 MBq (30-200 mCi) is used for the treatment of thyroid cancer (1). Regarding Turkey Atomic Energy Authority radiation protection legislation, patients who underwent therapy with more than $600 \mathrm{MBq}(16.2 \mathrm{mCi})$ at a time should be isolated in radionuclide therapy rooms in nuclear medicine clinics until the radiation dose rate decreases to $<30 \mu \mathrm{sv} / \mathrm{h}$ at 1 meter (2). In all radionuclide applications for diagnosis and treatment, pregnancy status of female patients of reproductive age are questioned and pregnancy test is requested in every suspicious case. Despite these precautions, ${ }^{131}$ I treatment may be applied to the pregnant women by accident in the first 10 days of pregnancy or in case of false negative pregnancy test results. In these applications, ${ }^{131}$ | reaches the placenta by metabolic pathways and irradiates the embryo/fetus. Fetal thyroid gland develops starting from the $10^{\text {th }}$ week of pregnancy. The ${ }^{131}$ I radionuclide 
concentrates in the thyroid gland of the fetus as well as in the mother's thyroid gland and participates in hormogenesis such as the non-radioactive iodine element. Therefore, ${ }^{131}$ I causes high fetal thyroid dose especially with beta rays during its stay in fetal thyroid gland $(3,4)$. In radiopharmaceutical applications, the radiation dose to which the embryo/fetus is exposed and the fetal thyroid dose can be calculated using various phantoms. The most commonly used of these phantoms are pregnant women phantoms developed by Stabin (5). Stabin's pregnant women models mimic the first period of pregnancy, 3 months, 6 months and 9 months of pregnancy. Russell et al. (6) calculated the radiation doses delivered to the embryo/fetus by radiopharmaceuticals used in nuclear medicine by using Stabin's pregnant female phantoms and presented the results in tables as $\mathrm{mG} / \mathrm{MBq}$ dose units. It is known that radiation has deterministic effects on embryo/fetus in prenatal period, including intrauterine death, organ malformations, growth developmental retardation, and mental retardation. To see these effects, the radiation dose to which the embryo/fetus is exposed must exceed a certain threshold. It has been shown that the cumulative radiation dose that may be harmful to the embryo/fetus is $50 \mathrm{mGy}(5 \mathrm{rad})$, but if the radiation exposure is below this amount during the entire pregnancy period, the embryo/fetus is far from deterministic effects and the risk of congenital anomalies does not increase significantly (7-11). There is no threshold dose in the theory of radiation-induced cancer, known as stochastic effect. In general, it is accepted that the embryo/fetus is more sensitive to ionised radiation and protective measures have been proposed (6). According to the generally accepted approach to termination of pregnancy, if the embryo/fetus is exposed to radiation doses higher than 100 mGy, the family should be given teratological counseling, and accurate, realistic and scientific information should be provided on the possible effects of ionized radiation and the risks to the baby. The decision to terminate the pregnancy should be made by the parents in accordance with the information provided by medical experts (12). If the embryo/fetus is exposed to radiation doses of more than $100 \mathrm{mGy}$ between the $10^{\text {th }}$ and $25^{\text {th }}$ weeks of pregnancy, termination of pregnancy is recommended due to the increased risk of fetal malformation, central nervous system damage, and growth and developmental retardation $(7,13)$. Stochastic effects on the embryo/fetus have been reported to occur at doses of 100-200 mGy $(14,15)$. The aim of this study was to determine the embryo/fetus dose and to evaluate the termination status of the pregnant women who underwent ${ }^{131}$ I in nuclear medicine centers.

\section{METHODS}

The study was initiated following the approval of the İstanbul University Cerrahpaşa Faculty of Medicine Ethics Committee (approval number: 219488, dated: 09/07/2015).

\section{Patient Groups}

According to the procedure in Cerrahpaşa Faculty of Medicine, pregnant women who accidently underwent radioactive investigation apply to the department of medical genetics. Patients whose gestational age is determined here by ultrasonography are referred to the department of nuclear medicine for calculation of the embryo/fetus dose and then referred back to the department of medical genetics. In this study, the embryo/fetus dose of 16 patients who underwent diagnostic and therapeutic 1311 at different nuclear medicine centers between July 2015 and June 2017 was computed in the nuclear medicine department. Of these patients, three patients with HTT underwent diagnostic $0.37 \mathrm{MBq}(10 \mu \mathrm{Ci}){ }^{131}$ I for TU, six patients who underwent thyroidectomy received $1.85 \mathrm{MBq}$ (0.05 mCi) ${ }^{131}$ I for TU scintigraphy (TUS), three patients received $185 \mathrm{MBq}$ (5 mCi) ${ }^{131}$ I for whole body scintigraphy (WBS), and two patients received therapeutic ${ }^{131}$ I for HTT and two patients received therapeutic ${ }^{131}$ I for thyroid cancer treatment (TCT). On the day of radiotherapy, 15 of the patients were in the first 3 months of pregnancy and one of them was in the $4^{\text {th }}$ month.

\section{Calculation and Evaluation of Embryo/Fetus Dose/Fetal Thyroid Dose}

The radiation doses (mGy/MBq) given to the embryo/fetus by the radiopharmaceuticals administered to the mother during various periods of pregnancy were calculated from phantoms by Russell et al. (6) (Table 1) (12). Fetal thyroid gland develops starting from the $10^{\text {th }}$ week of pregnancy. Taking into account this criterion in the calculation of fetus doses in our study, fetal thyroid dose was also calculated in fetuses with at least 10 weeks of gestation. The calculation of fetal thyroid dose was based on the table published by Watson (3) (Table 2). In accordance with

Table 1. Doses per unit activity (MBq) given to the embryo/fetus (mGy) from radioiodine 131 radionuclide administered to the mother (6)

\begin{tabular}{|l|l|l|l|l|}
\hline Radiopharmaceutical & Early period & 3 months & 6 months & 9 months \\
\hline${ }^{131}$ I sodium iodide & $7.2 \times 10-2 \mathrm{mGy} / \mathrm{MBq}$ & $6.8 \times 10-2 \mathrm{mGy} / \mathrm{MBq}$ & $2.3 \times 10-1 \mathrm{mGy} / \mathrm{MBq}$ & $2.7 \times 10-1 \mathrm{mGy} / \mathrm{MBq}$ \\
\hline${ }^{131}$ : Radioiodine 131 &
\end{tabular}


the routine application protocol of our study team, after the embryo/fetus dose is calculated in the department of nuclear medicine, the final report is submitted to the expectant mother and then directed to the department of medical genetics. Cases with embryo/fetus and fetal thyroid doses more than 100 mGy are re-referred to the outpatient clinic of the department of medical genetics. The medical genetic specialist determines the other teratogenic factors of the pregnant woman and sends the risk report to the obstetrician. As a result, the termination proposal is made by the physician to the parents and the decision is made by the parents.

\section{Statistical Analysis}

The data in this study were evaluated in detail and no statistical analysis was performed.

\section{RESULTS}

The study cohort consisted of pregnant women who underwent diagnostic and therapeutic nuclear medicine applications for thyroid diseases in different centers around Turkey. Mean embryo/fetus dose of three patients, who received $0.37 \mathrm{MBq}(10$ $\mu \mathrm{Ci}){ }^{131} \mathrm{I}$ orally for TU test, was calculated as $0.063 \mathrm{mGy}$. Fetal thyroid doses were not calculated since thyroid formation did not occur because the gestational age of the patients was less than 10 weeks. In six patients who underwent total thyroidectomy with the diagnosis of thyroid cancer, $1.85 \mathrm{MBq}(50 \mu \mathrm{Ci}){ }^{131}$ I was administered orally for the diagnosis of residual thyroid tissue and TUS was performed for diagnostic purposes. Three of these patients had gestational age less than 10 weeks and two of them had gestational age more than 10 weeks. The calculated mean fetal dose was 0.13 mGy and fetal thyroid dose was 1073 mGy (1.073 Gy). In patients undergoing total thyroidectomy and ${ }^{131}$ I therapy, WBS is usually performed at 6-12 months after ${ }^{131}$ I therapy for ablation control and metastasis research. In this

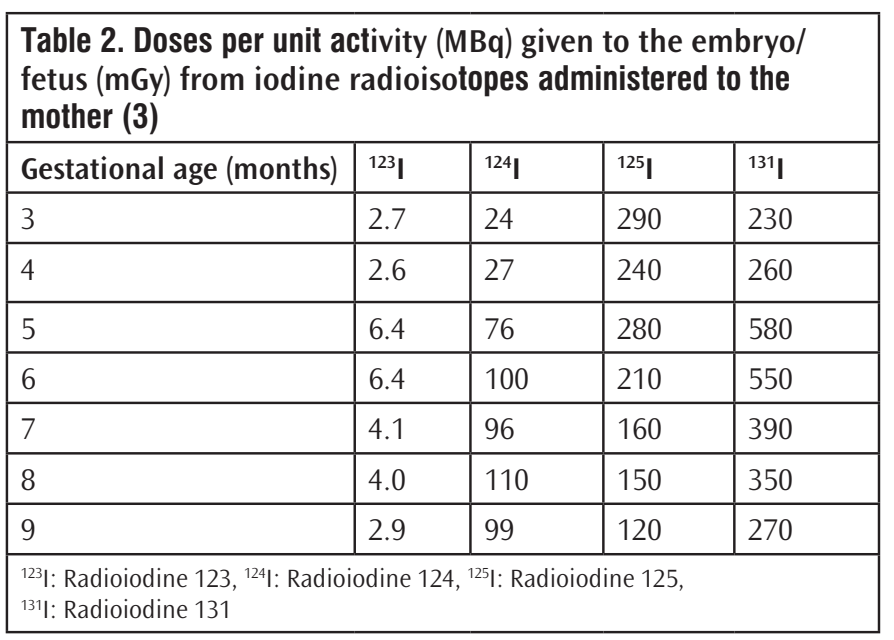

diagnostic study, $185 \mathrm{MBq}(5 \mathrm{mCi})^{131}$ I was administered orally to each of the three patients. Since the gestational age of the patients was less than 10 weeks, only embryo/fetus doses were calculated and the mean value was $13.2 \mathrm{mGy}$. The gestational age of one of the two patients undergoing HTT was 11 weeks-5 days, and $481 \mathrm{MBq}(13 \mathrm{mCi})^{131}$ I was administered orally to this patient. The fetal dose was $26.64 \mathrm{mGy}$ and the fetal thyroid dose was 215340 mGy (215.34 Gy). Since the other patient with HTT had a 3 week-0 day pregnancy, only the embryo/fetus dose was calculated and found as $34.63 \mathrm{mGy}$. One of the two patients who underwent TCT received $3700 \mathrm{MBq}(100 \mathrm{mCi}){ }^{131} \mathrm{I}$ and the embryo/fetus dose was $266.64 \mathrm{mGy}$. The patient who received $5555 \mathrm{MBq}(150 \mathrm{mCi})^{131}$ I was 15 weeks pregnant, and the fetus dose was $377.8 \mathrm{mGy}$ and the fetus thyroid dose was $3221.9 \mathrm{~Gy}$ (Table 3). Following labor, 13 out of 16 women were followed up. One woman who had TU and two women who had TUS could not be followed up. Of the 13 women who were followed up, two women who underwent TU had vaginal birth with healthy babies, and their thyroid hormone tests and mental performance tests were found to be normal. Two of six women who had TUS could not be followed up. Radiotherapy was planned for breast cancer in one of the four women who were followed up and medical abortion was performed. The remaining three women had vaginal birth, and one of the babies had hypothyroidism and the other two babies had normal thyroid hormone tests and mental performance tests. One of the three women who had WBS examination delivered stillbirth in the $24^{\text {th }}$ week of pregnancy and the other two had healthy babies with vaginal birth. One of the two women who underwent HTT had medical abortion due to high fetal thyroid dose exposure, the other gave birth to a healthy baby with normal delivery, and thyroid hormone tests and mental performance tests of the baby were found to be normal. Two women who had underwent TCT underwent medical abortion due to high fetal dose and high fetal thyroid dose. The mean values of the calculated embryo/fetus doses are shown in Figure 1. In ${ }^{131} \mathrm{I}$ applications, it was determined that embryo/fetus dose was low in patients with gestational age less than 10 weeks and fetal thyroid dose increased significantly in gestational age more than 10 weeks. It was observed that both embryo/fetus dose and fetal thyroid dose were at very high levels due to high iodine activities applied for TCT (Figure 2).

\section{DISCUSSION}

The embryo/fetus is highly sensitive to radiation. The ${ }^{131}$ I radionuclide used in the diagnosis and treatment of thyroid diseases is an important risk to the embryo/fetus when taken into the body of the pregnant woman because of its characteristics 
such as high energy beta and gamma rays and relatively long physical half-life. It is recommended that fetal thyroid dose be calculated in order to determine the risk ratio (3). It has been known for many years that fetal thyroid develops at the $10^{\text {th }}$ week of pregnancy and it concentrates the iodine element (16). Stabin, (17) one of the authorities on this issue, reported that thyroid functions may be completely lost in higher doses as well as thyroid dysfunction may be observed as a result of high dose exposure of fetal thyroid during pregnancy. It is known that the ${ }^{131}$ I applied to the expectant mother passes through the placenta by active transport mechanism like the non-radioactive iodine element and mixes with the fetal blood and that the iodine

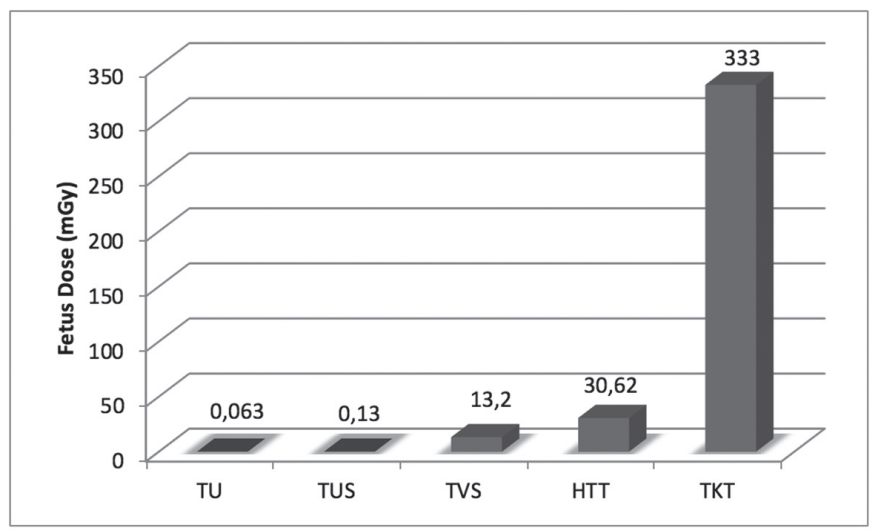

Figure 1. Distribution of mean embryo/fetus doses in diagnostic and therapeutic radioiodine 131 administration

TU: Thyroid uptake, TUS: Thyroid uptake scintigraphy, HTT: Treatment of hyperthyroidism, TCT: Thyroid cancer treatment concentration in the fetal blood is $75 \%$ in the mother's blood. During thyroid hormone synthesis using the ${ }^{131}$ I element, fetal thyroid tissue is exposed to radiation. While beta rays of ${ }^{131}$ I give high radiation dose to fetal thyroid tissue, gamma rays give radiation dose to both fetal thyroid and whole fetus (18). The radiation dose delivered to a fetal thyroid tissue by ${ }^{131} \mathrm{I}$ applied to a 12 week old pregnant woman was evaluated as $350 \mathrm{mGy} /$ MBq by Roedler (19) and as $220 \mathrm{mGy} / \mathrm{MBq}$ by Johnson (20). In our study, the calculated fetal thyroid dose was $230 \mathrm{mGy} / \mathrm{MBq}$ in an 11 week pregnant woman. After ${ }^{131}$ I is administered to a woman with unknown pregnancy, dosimetry is required to determine the radiation dose received by the embryo/fetus.

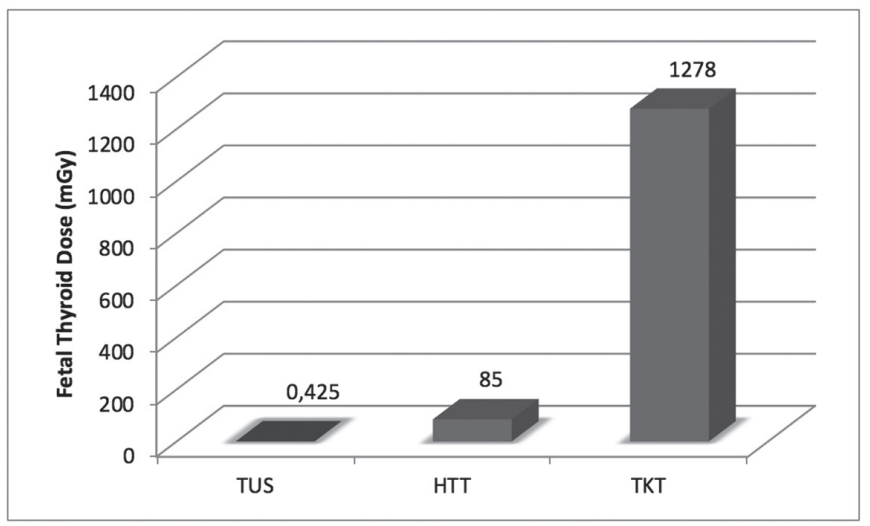

Figure 2. Distribution of mean fetal thyroid doses in diagnostic and therapeutic radioiodine 131 administration

TUS: Thyroid uptake scintigraphy, HTT: Treatment of hyperthyroidism, TCT: Thyroid cancer treatment

\begin{tabular}{|c|c|c|c|c|c|c|}
\hline & $\begin{array}{l}\text { Patient no } \\
\text { application } \\
\text { purpose }\end{array}$ & $\begin{array}{l}\text { Dose applied } \\
\text { MBq (mCi) }\end{array}$ & $\begin{array}{l}\text { Gestational } \\
\text { age (week, } \\
\text { day) }\end{array}$ & $\begin{array}{l}\text { Embryo/fetus } \\
\text { dose (mGy) }\end{array}$ & $\begin{array}{l}\text { Fetal thyroid } \\
\text { dose (mGy) }\end{array}$ & Pregnancy follow up \\
\hline $\begin{array}{l}\text { Low dose } \\
\text { (diagnostic) }\end{array}$ & $\begin{array}{l}\text { 1. TU } \\
\text { 2. TU } \\
\text { 3. TU } \\
\text { 4. TUS } \\
\text { 5. TUS } \\
\text { 6. TUS } \\
\text { 7. TUS } \\
\text { 8. TUS } \\
\text { 9. TUS } \\
\text { 10. WBS } \\
\text { 11. WBS } \\
\text { 12. WBS } \\
\end{array}$ & $\begin{array}{l}0.37(0.01) \\
0.37(0.01) \\
0.37(0.01) \\
1.85(0.05) \\
1.85(0.05) \\
1.85(0.05) \\
1.85(0.05) \\
1.85(0.05) \\
1.85(0.05) \\
185(5) \\
185(5) \\
185(5) \\
\end{array}$ & $\begin{array}{l}3 w, 3 d \\
3 w, 1 d \\
6 w, 2 d \\
2 w, 5 d \\
11 w, 4 d \\
2 w, 5 d \\
10 w, 3 d \\
5 w, 5 d \\
3 w, 5 d \\
5 w, 2 d \\
6 w, 3 d \\
2 w, 4 d\end{array}$ & $\begin{array}{l}0.063 \\
0.063 \\
0.063 \\
0.13 \\
0.12 \\
0.13 \\
0.12 \\
0.13 \\
0.13 \\
13.2 \\
13.2 \\
13.2 \\
\end{array}$ & $\begin{array}{l}- \\
- \\
- \\
- \\
425(0.425 \mathrm{~Gy}) \\
- \\
425(0.425 \mathrm{~Gy}) \\
- \\
- \\
- \\
- \\
-\end{array}$ & $\begin{array}{l}\text { Live, healthy birth } \\
\text { Live, healthy birth } \\
\text { Out of follow-up } \\
\text { Medical abortion Live, } \\
\text { healthy birth } \\
\text { Out of follow-up } \\
\text { Live, healthy birth } \\
\text { Out of follow-up } \\
\text { Live, healthy birth } \\
\text { Live, healthy birth } \\
\text { Stillbirth } \\
\text { Live, healthy birth }\end{array}$ \\
\hline $\begin{array}{l}\text { High dose } \\
\text { (treatment) }\end{array}$ & $\begin{array}{l}\text { 11. HTT } \\
\text { 12. HTT } \\
\text { 13. ТCT } \\
\text { 14. ТCT }\end{array}$ & $\begin{array}{l}370(10) \\
481(13) \\
3700(100) \\
5555(150)\end{array}$ & $\begin{array}{l}11 \mathrm{w}, 5 \mathrm{~d} \\
3 \mathrm{w}, 0 \mathrm{~d} \\
2 \mathrm{w}, 3 \mathrm{~d} \\
13 \mathrm{w}, 0 \mathrm{~d}\end{array}$ & $\begin{array}{l}26.64 \\
34.63 \\
266.4 \\
377.8 \\
\end{array}$ & $\begin{array}{l}85100 \text { (85.1 Gy) } \\
- \\
- \\
1277650 \text { (1277.6 Gy) }\end{array}$ & $\begin{array}{l}\text { Medical abortion } \\
\text { Live, healthy birth } \\
\text { Medical abortion } \\
\text { Medical abortion }\end{array}$ \\
\hline
\end{tabular}


In Report 54 of the National Council on Radiation Protection and Measurements, fetal dose exposures below 50 mGy (5 rad) are reported to be negligible in terms of congenital risk when compared to natural risks in pregnancy (21). This organization reported that if the embryo/fetus dose is greater than $150 \mathrm{mGy}$ (15 rad); the risk of malformation may be uncontrollably high. Otake et al. (22) examined the effects of the atomic bomb on Japanese pregnant women and reported that embryo/fetus was the most sensitive to radiation between $8^{\text {th }}$ and $15^{\text {th }}$ weeks of pregnancy. In the Committee on the Biological Effects of Ionizing Radiation $V$ report evaluating the effects of radiation on fetus, it was reported that the radiation dose to be given to the fetus by ${ }^{131}$ I radionuclide with $3700-7400 \mathrm{MBq}$ activity for therapeutic purposes by accident between $8^{\text {th }}$ and $15^{\text {th }}$ weeks of pregnancy will exceed the threshold value (23). The International Commission on Radiological Protection-84 report stated that if the fetal dose is $>10 \mathrm{mGy}$, the risk of leukemia and cancer may increase by $40 \%$, and that if the fetus dose is 100-1000 mGy, pregnancy should be terminated (24). Maxon and Smith (25) reported that the total dose required to ablate residual thyroid tissue in patients undergoing total thyroidectomy for TCT was $300 \mathrm{~Gy}$. If a high-dose ${ }^{131}$ I is administered to an expectant mother at the $10^{\text {th }}$ gestational week, the fetal thyroid dose exceeds the $300 \mathrm{~Gy}$ limit in most cases. In addition, thyroid gland is evaluated in the critical organs group in terms of radiation dose and the tolerance dose has been reported as 20 Gy (26-28). In such cases, fetal thyroid dose should be determined and teratological counseling should be given to the family. In addition, pregnancy test should be performed before radioactive applications in any suspicious cases. If ${ }^{131} \mathrm{I}$ is applied to a pregnant woman by accident in diagnostic tests such as TU and/or TUS, it is useful to make the patient drink plenty of water to accelerate urinary excretion (29).

\section{CONCLUSION}

According to the results of this study, it is concluded that patientspecific embryo/fetus dose estimation is necessary for pregnant women who received radioiodine in pregnant women who received ${ }^{131}$ I radionuclide, ${ }^{131}$ I which is applied for diagnostic purposes before the $10^{\text {th }}$ week of pregnancy will not deliver radiation dose enough to cause anomalies in the embryo alone, and that ${ }^{131}$ I radionuclide administered in the treatment of HTT and thyroid cancer after the $10^{\text {th }}$ week of pregnancy can be an indication for medical abortion due to increasing fetus dose above 100 mGy and fetal thyroid dose above 20 Gy.

\section{Ethics}

Ethics Committee Approval: The study was initiated following the approval of the İstanbul University Cerrahpaşa Faculty of Medicine Ethics Committee (approval number: 219488, dated: 09/07/2015).

Informed Consent: Informed consent from was patient.

Peer-review: External and internal peer-reviewed.

\section{Authorship Contributions}

Concept: M.D., İ.Ç., M.S., Design: M.D., M.S, M.A., L.U.B., Data Collection or Processing: N.Y., N.I.., M.B.D., Analysis or Interpretation: L.U.B., M.B.D., Literature Search: M.D., I.Ç., M.A., Writing: M.D., L.U.B., M.A.

Conflict of Interest: No conflict of interest was declared by the authors.

Financial Disclosure: The authors declared that this study received no financial support.

\section{REFERENCES}

1. Uslu Beşli L, Demir M. Radiation in Thyroid Cancer Patients. Hojjat Ahmedzaedfar, editors. Thyroid cancer-Advanced in Diagnosis and Therapy. Rejeka, Croatia: Intech 2016,229-45.

2. Türkiye Atom Enerjisi Kurumu (TAEK) Radyasyon Güvenlik Yönetmeliği, 2000.

3. Watson EE. Radiation absorbed dose to the human fetal thyroid. In :Fifth International Radiopharmaceutical Dosimetry Symposium. Oak Ridge, TN: Oak Ridge Associated Universities 1992,170-187.

4. Stabin MG, Siegel JA, Sparks RB, Eckerman KF, Breitz HB. Contribution to red marrow absorbed dose from total body activity: a correction to the MIRD method. J Nucl Med 2001;42:492-8.

5. Stabin MG. Radiation dose concerns for the pregnant or lactating patient. Semin Nucl Med 2014;44:479-88.

6. Russell JR, Stabin MG, Sparks RB, Watson E. Radiation absorbed dose to the embryo/fetüs from radiopharmaceuticals. Health Phys 1997;73:756-69.

7. Barent RL. Saving lives and changing family histories: appropriate counseling of pregnant women and men and women of reproductive age, concerning the risk of diagnostic radiation exposures during and before pregnancy. Am J Obstet Gynecol 2009;200:4-24.

8. International Commission on Radiological Protection. Pregnancy and Medical Radiation. ICRP Publication 84. Ann ICRP 2000;30:1-43.

9. Wagner LK, Lester RG, Saldana LR, editors. Exposure of the pregnant patient to diagnostic radiations. 2nd ed. Madison: Medical Physics Publishing Corporation;1997.

10. American Coolege of Radiology. AcoR 05-05 bylaws. Reston, Va: American Collage of Radiology, 2005.

11. Brent RL. Utilization of juvenile animal studies to determine the human effects and risks of environmental toxicants during postnatal developmental stages. Birth Defects Res B Dev Reprod Toxicol 2004;71:303-20.

12. Stabin MG. Radiation dose and risks to fetus from nuclear medicine procedures. Physica Medica 2017;43,190-8. 
13. Hall EJ, Giarccia AJ. Effect of radiation on the embryo and fetüs. Radiobiology fort he radiologist. 6th.ed. Philadelphia: Lippincott. 2006;168-80.

14. Ratnapalan S, Bona N, Chandra K, Koren G. Physicians' perceptions of teratogenic risk associated with radiography and CT during early pregnancy. AJR Am J Roentgenol 2004;182:1107-9.

15. Preston DL, Cullings H, Suyama A, Funamoto S, Nishi N, Soda M, et al. Solid cancer incidence in atomic bomb survivors exposed in utero or as young children. J Natl Cancer Inst 2008;100:428-36.

16. Cloutier RJ, Smith SA, Watson EE, Snyder WS, Warner GG. Dose to the fetus from radionuclides in the bladder. Health Phys 1973;25:147-61.

17. Stabin MG, Watson EE, Marcus CS, Salk RD. Radiation dosimetry for the adult female and fetüs from iodine-131 administration in hyperthyroidism. J Nucl Med 1991;32:808-13.

18. Watson EE. Radiation absorbed dose to the human fetal thyroid. Fifth International Radiopharmaceutical Dosimetry Symposium,May 7-10,1992 Oak Ridge, Tennessee-USD.

19. Roedler HD. Assessment of fetal activity concentration and fetal dose for selected radionuclides based on animal and human data. Age-related Factors in Radionuclide Metabolism and Dosimetry. GB Gerber, H Metivier, and H Smith, editors. Dordrecht: Martinus Nijh off Publishers; 1987.p.32737.

20. Johnson JR. A review of age dependant radioiodine dosimetry. Agerelated Factors in Radionuclide Metabolism and Dosimetry. GB Gerber, H Metivier, and H Smith, editors, Dordrecht: Martinus Nijhoff Publishers; 1987.p.24959.

21. National Council on Radiation Protection and Measurements. Medical radiation exposure of pregnant and potentially pregnant women. NCRP report no. 54. Bethesda, MD: National Council on Radiation Protection and Measurements; 1977.
22. Otake M, Yoshimaru H, Schull W. Severe mental retardation among the prenatally exposed survivors of the atomic bombing of Hiroshima and Nagasaki: a comparison of the T65DR and DS86 dosimetry systems. RERF TR 16-87. Radiation Effects Research Foundation, Japan, 1988.p.40.

23. Committee on the Biological Effects of Ionizing Radiations. Health effects of exposure to low levels of ionizing radiation, BEIR V. Washington, DC: National Academy Press; 1990.

24. International Commission on Radiological Protection. Pregnancy and medical radiation. Ann ICRP 2000;30,1-43.

25. Maxon HR, Smith HS. Radioiodine-131 in the diagnosis and treatment of metastatic well differentiated thyroid cancer. Endocrinol Metab Clin North Am 1990;19:685-718.

26. Tunio MA, Al Asiri M, Bayoumi Y, Stanciu LG, Al Johani N, Al Saeed EF. Is thyroid gland an organ at risk in breast cancer patients treated with locoregional radiotherapy? Results of a pilot study. J Cancer Res Ther 2015;11:684-9.

27. Alterio D, Jereczek-Fossa BA, Franchi B, D’Onofrio A, Piazzi V, Rondi E et al. Thyroid disorders in patients treated with radiotherapy for head-and-neck cancer: a retrospective analysis of seventy-three patients. Int J Radiat Oncol Biol Phys 2007;67:144-50.

28. Emami B, Lyman J, Brown A, Coia L, Goitein M, Munzenrider JE, et al. Tolerance of normal tissue to therapeutic irradiation. Int J Radiat Oncol Biol Phys 1991;21:109-22.

29. Sabbir Ahmed AS, Demir M, Yasar D, Uslu I. Quantification of absorbed doses to urine bladder depending on drinking water during radioiodine therapy to thyroid cancer patients: a clinical study using MIRDOSE3. Nucl Med Commun 2003;24:749-54. 